\title{
ANÁLISIS
}

\section{¿Del siglo norteamericano al siglo del Pacífico asiático? ${ }^{1}$}

DOI: $10.32870 /$ mycp.v13i39.347

Manfred Mols ${ }^{2}$

$\mathrm{E}$

$\mathrm{n}$ el inicio de estas reflexiones ${ }^{3}$ hay que recordar la visión del presidente americano Theodore Roosevelt, quien hace cerca de cien años dijo lo siguiente: "La era atlántica se encuentra actualmente en la cima de su desarrollo, pero pronto agotará sus recursos disponibles. La era Pacífico, que será la mayor de todas, apenas está iniciando su marcha". En su tiempo, Roosevelt no tenía a la mano muchos indicadores. La única potencia asiática que en ese entonces buscaba vínculos con Occidente y ya tenía establecidos algunos contactos era Japón. En la literatura contemporánea, la frase de Roosevelt ha sido formulada con mayor precisión y actualizada: "La era Pacífico será gobernada por China y por nadie más". ${ }^{5}$ En la investigación alemana sobre Asia existe una versión que habla del centralismo creciente de

1. Esta es una versión en español del artículo "Vom Amerikanischen zu einem Asiatisch-Pazifischen Jahrundert?”, publicado por el autor en la revista KAS-Auslandsinformationen Nr. 9/09, ed. Konrad Adenauer Stiftung, pp. 7-80. Es publicado con el permiso de la editorial.

2. El Dr. Manfred Mols fue, hasta su jubilación, profesor de ciencias políticas en la Universidad de Mainz. Fue profesor huésped en la Universidad de Stanford, en la Universidad Iberoamericana en México, en la Universidad Hebrea de Jerusalén y en la Universidad Nacional de Australia, en Canberra. Ha colaborado en numerosos proyectos de investigación alemanes e internacionales. Entre 1995 a 2000 colaboró en el proyecto de la UNEsco "Un estudio crítico de la historia", dirigido por el profesor Helio Jaguaribe de Matoos.

3. Agradezco a mi esposa Dietlinde por su crítica constructiva. También agradezco los útiles señalamientos de Claudia Derichs, Jörn Dösch, Wolf Grabendorff, Christoph Müller-Hofstede, Dirk Nabers y Dieter Senghaas.

4. Citado por Parag Khanna, Der Kampf um die Zweite Welt. Imperien und Einfluss in der neuen Weltordnung, Berlín, 2008.

5. Ibídem. 
la República Popular de China. ${ }^{6}$ ¿Será China?, ¿únicamente ella? Y, ¿ significa "era" lo mismo que "siglo"?

\section{Introducción}

En 1941, Henry Luce, el editor fundador de la revista norteamericana Time, llamó al siglo xx el siglo norteamericano. La pretensión y la realidad parecían coincidir. A pesar del desafío militar en el Lejano Oriente, los Estados Unidos de América estaban seguros que la guerra en el Pacífico contra Japón terminaría a su favor. Lo mismo preveían en la guerra contra la coalición de Hitler. Además de ser con mucho la potencia militar más fuerte de la Tierra $\mathrm{y}$, a partir del verano de 1945, poseer el monopolio de las armas nucleares por un tiempo considerable, los EEUU lograron tejer una red de alianzas bi y multilaterales bajo su dirección, como la OTAN, el Pacto de Seguridad Interamericano de Petrópolis y el Tratado de Defensa con Japón y Corea del Sur. En sus dimensiones globales, esta red de alianzas era algo desconocido hasta entonces en la historia mundial. A diferencia de lo ocurrido después de la I Guerra Mundial, los Estados Unidos consiguieron imponer nuevas estructuras en el sistema internacional mediante la fundación de la Naciones Unidas, la Organización de los Estados Americanos y una red global de organizaciones dependientes de la ONU que trabajan en ámbitos específicos, como el Fondo Monetario Internacional, el Banco Mundial, el Programa para el Desarrollo UNDP, UNESCO, FAO, etc. Algunas de ellas se convirtieron de facto en un contrapeso al comunismo, que en ese entonces se expandía por casi todo el mundo conducido principalmente por la Unión Soviética.

En este tiempo y por muchos años, los Estados Unidos ejercieron un liderazgo global reconocido en Europa central y occidental, casi toda Latinoamérica, amplias zonas de la región Asia-Pacífico y la mayor parte de los Estados africanos y sudasiáticos que buscaba su independencia y que lo aceptaban con gusto. Pues Washington exigía la descolonización y el estilo de economía y de vida americanos eran considerados como modelos a seguir. Durante décadas, el dólar norteamericano fue la principal divisa del mundo $\mathrm{y}$, a pesar de las disputas internacionales sobre su estabilidad y la presión

6. Véase Maull, Hanns W. y Martin Wagner (editores), Ostasien in der Globalisierung, BadenBaden, 2009. Lo que cito aquí casi literalmente proviene de la introducción escrita por los editores. 
temporal del euro, hasta ahora así se ha mantenido. Estados Unidos logró convertirse en la principal potencia económica mundial, que por años generó cerca de $50 \%$ del producto industrial global. De los norteamericanos salieron decisivos impulsos de modernización en la ciencia y en la tecnología que se manifestaron, entre otros, en la cantidad impresionante de estadounidenses que obtuvieron el Premio Nobel. Y, con todo el gran respeto que merecen las prestigiadas e influyentes universidades europeas y las que surgieron en Asia, hay que señalar que con Harvard, Princeton, Stanford, Columbia, el MIT, Yale, etc., los Estados Unidos se encontraron al frente de las instituciones académicas de mayor prestigio, y con una considerable distancia en relación al "resto del mundo", una tendencia que todavía hoy en día se mantiene.

Un argumento decisivo, que explica la fuerza de penetración global de los EEUU, es decir, una justificación fundamental para hablar de un siglo norteamericano, se encuentra en el amplio ámbito cultural al que Joseph $\mathrm{Nye}^{7}$ hace años se refirió en las discusiones sobre política internacional y que ahora tiene un lugar en el debate político chino: el soft power. Soft power es la emanación cultural y civilizatoria de una entidad sociopolítica hacia fuera, es decir, la fuerza de atracción paradigmática que ejerce sobre otros. En este sentido, los Estados Unidos han sido por décadas una especie de faro de soft power global, apoyados considerablemente por Hollywood, sus medios de comunicación, la apertura de los sitios de formación e investigación para estudiantes e investigadores de prácticamente todo el mundo, las formas de un comportamiento social sin complicaciones en la vida cotidiana, etc. Se buscaba ser similar a los estadounidenses, aunque con el cuidado de no renunciar totalmente a la propia identidad cultural. No es posible delimitar el concepto de soft power de manera precisa en todas sus aristas. De ahí que también el modelo de economía capitalista dictado por los estadounidenses - hasta ahora una de las ideas dominantes para la estructuración de la economía - pueda ser colocado bajo el rubro de soft power.

En la fuerza de imposición y en la aceptación del siglo norteamericano han surgido fracturas, dudas crecientes sobre su permanencia y conveniencia. De esto trata la primera mitad de este artículo. Por el momento, no será posible dar una respuesta definitiva a la pregunta, si el siglo norteamericano será

7. Un artículo al respecto apareció hace años en la revista Foreign Affairs. Véase una de sus más recientes publicaciones: Das Paradox der amerikanischen Macht. Warum die einzige Supermacht del Welt Verbündete braucht, Nueva York, 2002. 
sustituido por uno del Pacífico asiático o eventualmente por uno chino. De cualquier modo, estamos ante un cambio claramente visible en el proceso de la historia contemporánea que señala direcciones, pero no permite ningún pronóstico exacto.

\section{Sobre el concepto "siglo" y su relación con la influencia norteamericana}

Desde hace décadas, los Estados Unidos muestran un impresionante perfil de poder e influencia en ámbitos que van desde la esfera militar hasta la mayoría de los campos que definen la realidad política, social y económica, y que la Unión Soviética ni en sus mejores años pudo igualar en sus primeros niveles. En muchas partes del mundo, el concepto de American Age pasó a ser una fórmula de entendimiento, cuanto más que hubo un tratamiento histórico serio por parte de los científicos. ${ }^{8}$ En aquellos años de competencia entre los sistemas, Washington no tenía la intención de hacer a Europa a un lado. Pero si la "civilización occidental tardía" constituye el impulso cultural y civilizatorio de nuestra época — como señala el estudio de la UNESCO sobre las civilizaciones occidentales y sus efectos-, ${ }^{9}$ entonces es la occidentalidad la fuerza más influyente del siglo Xx. Y ésta no se puede definir, especialmente en la época posterior a la II Guerra Mundial, sin la clara y determinante contribución estadounidense.

La globalización cada vez más densa que vivimos desde hace dos décadas y que discutimos mundialmente surgió de Occidente con una participación considerable de los EEUU, aun cuando el inicio de la globalización se pueda marcar con la era de los descubrimientos, es decir, con el ascenso de Europa a la política mundial. En una retrospectiva histórica, tenemos ante nosotros un fenómeno que jamás se había dado. En la escuela conocemos los "imperios mundiales", como el Imperio romano o la China imperial, para nombrar sólo dos de los más importantes. Pero, en realidad estos imperios fueron grandes espacios geopolíticos y culturales con una influencia limitada en sus respectivos entornos "bárbaros", ${ }^{10}$ incluso ahí donde en ambos lados, el lado de los

8. Véase Walter Lafeber, The American Age. United States Foreign Policy at Home and Abroad Since 1750, Nueva York y Londres, 1989.

9. Véase Helio Jagauribe, Um estudio critico da história, Säo Paulo, 2001 (2 vols.).

10. La tesis que se escucha frecuentemente de que China regresa ahora a la política mundial es producto de la fantasía, cuyos propagandistas no contemplan el centralismo del "imperio del 
"imperios" como el de los "bárbaros", existía atracción por las ventajas de la aculturación.

La primera potencia capaz de imponerse mundialmente fue el Imperio británico, que logró convertirse en la fuerza de mayor peso en la política mundial debido no solamente a su extensión y omnipresencia desde el siglo XVIII. Los impulsos que partieron de Gran

Por el momento, no será posible dar una respuesta definitiva a la pregunta, si el siglo norteamericano será sustituido por uno del Pacífico asiático o eventualmente por uno chino. De cualquier modo, estamos ante un cambio claramente visible en el proceso de la historia contemporánea que señala direcciones, pero no permite ningún pronóstico exacto Bretaña mostraron una fuerza de conformación global única. Se formuló un constitucionalismo que luego fue seguido como ejemplo. En la filosofía del Estado y en la teoría económica se colocaron las bases para el orden político válidas todavía hoy en día, con lo que se logró definir el sustento de la moderna política internacionaly el sistema económico mundial. En el último tercio del siglo XVIII, ahí empezó la industrialización moderna, incluyendo la del ferrocarril, que posteriormente revolucionó las condiciones de tráfico en continentes enteros. Sin embargo, las aportaciones británicas, como otras manifestaciones de importancia plasmadas en la historia, se quedaron atadas a su tiempo.

Ya en el transcurso del siglo XIX, se inició la entrega de la estafeta en el liderazgo de la política mundial a los Estados Unidos con empujes casi paralelos en Latinoamérica y en el espacio asiático-Pacífico. En la Europa continental, estas intervenciones imperialistas de los EEUU apenas han sido objeto de atención, pues los europeos se han visto a sí mismos durante largo tiempo como los principales portadores de la civilización mundial. La creciente influencia norteamericana en el mundo moderno y su peso, fortalecido por las dos guerras mundiales, fueron aceptados por razones de seguridad, pero

medio", además de que antes de la era de los descubrimientos no existía un mundo global y China era entonces sólo un factor político-cultural entre muchos otros. 
la estimación prevaleciente de la influencia norteamericana permaneció concentrada en el espacio Atlántico. Se consideraba como una visión pobre el intento por reducir la occidentalidad a los impulsos británicos y norteamericanos, pues lo proveniente de Italia, los Países Bajos, Francia, España, Portugal, y el espacio alemán, no podía de ninguna manera ser soslayado. No obstante, el Imperio británico y posteriormente los Estados Unidos, con sus fuerzas globales de penetración, incidieron de tal forma en el proceso de civilización que por primera vez en la historia de la humanidad afectaron a todos los continentes. Junto con sus potenciales de poder se convirtieron en el modelo de cultura para la vida cotidiana en muchas sociedades, países, grandes regiones, etc., por lo que se justifica plenamente la categorización de siglo británico y luego siglo estadounidense.

Visto así, el concepto de siglo aquí utilizado analíticamente abarca un campo más amplio que el concepto de "era" de Roosevelt. La expansión mundial del idioma inglés y el dominio anglosajón en los medios, que comprende una industria del entretenimiento muy diversa, contribuyeron a darle al concepto contenidos concretos y un sentido en lo que respecta a su influencia en los comportamientos.

\section{Asia entra en escena}

La fuerza con la que Asia apareció en la conciencia de las potencias coloniales europeas y, desde el inicio del siglo XIX, en los cálculos estratégicos norteamericanos se debió, en parte, a los intereses comerciales que acompañaron al imperialismo occidental y, en parte, a las ideas de la Ilustración que despertaron la curiosidad cultural por Asia oriental e India. Como contraparte, las ideas misionarias se orientaron a Asia. Hasta las primeras décadas del siglo xx, Occidente no vio en Asia ninguna amenaza, porque casi todos los países o zonas civilizadas, o bien se encontraban en las manos de las potencias coloniales europeas o los países asiáticos mismos se empeñaban en alcanzar con mayor o menor intensidad los estándares de modernidad del mundo occidental, entre ellos fue Japón el que lo buscó con mayor energía.

Ya en 1895, Japón era militarmente lo suficientemente fuerte para disputar a los chinos el dominio de Corea. Diez años más tarde, la marina de guerra japonesa vencía a los rusos, con lo que por primera vez en la era moderna una potencia asiática derrotaba a una europea. En ese entonces, Estados Unidos era ya tan influyente en Asia que las negociaciones de paz se llevaron a cabo 
en suelo norteamericano. En 1937, se inició la segunda guerra chino-japonesa, con lo que dio inició la II Guerra Mundial en el Lejano Oriente.

Después de la victoria sobre Japón, los norteamericanos urgieron una pronta descolonización —no solamente en Asia—, lo que sin la presión norteamericana sobre los europeos sin duda hubiera sido más difícil y seguramente se hubiera retrasado. Con el Acuerdo de alto al fuego de París en 1973 y el Acuerdo de paz entre Vietnam del Norte y los Eevu, la era del imperialismo occidental en Asia prácticamente llegó a su fin. Asia podía seguir su propio desarrollo. En algunos países, la oportunidad fue aprovechada de manera impresionante. Japón, y algunos años después también Corea, tuvieron un desarrollo industrial, económico y tecnológico rasante. Japón se convirtió en la segunda potencia económica del mundo y fue una pesadilla para los Estados Unidos por su exitosa competencia económica, hasta que la crisis de 1990 disminuyó su ritmo. Libros como el de George Friedman y Lebard Meredith ${ }^{11}$ The Coming War With Japan llamaron la atención, en ellos no se trataba de los preparativos para un nuevo conflicto militar con Japón, sino de evitar un conflicto sustancial ante la fuerza económica creciente del imperio insular en todos los principales mercados del mundo, no por último el de los Estados Unidos.

En un grupo de países del este y sureste asiático se presentó un crecimiento económico tal que a estos países se les denominó como "tigres". Este grupo estaba integrado por los Estados de Corea del Sur, Singapur, Hong Kong y Taiwán y seguía políticamente la exitosa historia japonesa del developmental state. El developmental state significaba una fuerte dirección económica del Estado involucrando por completo a la sociedad. Siguiendo al grupo de los tigres, países como Tailandia o Malasia se modernizaron considerablemente. Ya en los años treinta, los chinos y los japoneses implementaron el modelo Flying Geese, proveniente de la tradición confusionista. Su versión orientada a la economía de exportación, con sus potenciales de crecimiento, se aplicó en los años sesenta a Japón y al espacio del sureste asiático, donde Japón se veía a sí mismo en el papel del ganso volador en la posición de liderazgo.

Después de cierto retraso en sus fases de desarrollo, China vino a recuperar el terreno perdido. Fue Deng Xiao-ping quien puso fin a la revolución cultural y sus consecuencias y a partir de 1979 hizo posible el enorme crecimiento económico. Desde el punto de vista económico, este desarrollo convirtió a

11. Nueva York, 1991. 
China en la modernización más exitosa de la historia. Si bien es cierto que las tasas oficiales de crecimiento anual ${ }^{12}$ - que señalan un promedio de $10 \%$ - no fueron ni son confiables, ${ }^{13}$ en las últimas décadas los chinos lograron elevar considerablemente el ingreso per cápita de su población. A pesar de que aún se está lejos de alcanzar el nivel de ingreso del mundo occidental y de Japón, el crecimiento económico permitió el ascenso de $25 \%$ a $30 \%$ de la población, más de 1.3 mil millones de personas, a la clase media. Los chinos lograron, además, integrar al país a la economía mundial y afianzarse comercialmente en continentes ultramarinos como África, Latinoamérica y Australia.

De ahí que sea completamente comprensible la intranquilidad que China despierta en Estados Unidos y también en Europa. China ha superado el producto social bruto de Francia y desde hace tiempo se encuentra entre las mayores potencias económicas, después de los EEUU, Japón y Alemania. En 2007 , las exportaciones chinas, que alcanzaron un valor de 1,218 mil millones de dólares, superaron a las norteamericanas y se colocaron solamente detrás del volumen de exportación de Alemania. ${ }^{14}$ Esto último también podría cambiar en 2009 a favor de los chinos a raíz del significativo descenso del potencial económico derivado de la crisis financiera. Para subrayar todavía más la dinámica del crecimiento chino, hay que considerar el siguiente dato respecto al aumento de exportaciones: $:^{15}$ entre 1980 y 2007, Alemania pudo elevar sus exportaciones en un factor de casi 7, Estados Unidos en un factor de 4, Japón de 5.5, Reino Unido de 4, China de 67.

El significativo crecimiento de China debe ser considerado bajo dos puntos de vista:

1. Por su número de tropas, China se ha convertido en un poder militar considerable entre el este, sureste y el sur de Asia. Sus fuerzas de aire y

12. Véase Priewe, Jan, "Kein Ende in Sicht? Wirtschaftswachstum in China", en WeltTrends 53, Invierno 2006/2007, pp. 73-86, aquí véase la tabla de la página 77.

13. Serias dudas al respecto expresa, por ejemplo, Bell Emmott en Rivals. How the Power Struggle Between China, India and Japan will Shape our Next Decade, Orlando e.o.2008. Emmott fue 13 años jefe de redacción del Economist. Con más cuidado que Emmott, Priewe también se refiere a ello.

14. Véase "Bunsdeszentrale für politische Bildung: Informationen zur politischen Bildung: Internacionale Wirtschaftsbeziehungen", en Informationen zur politischen Bildung 299, 2, Cuartal, 2008.

15. Estos datos proceden de Wikipedia en la versión del 22.11.2008. Comercio mundial. Las tablas y gráficas han sido redondeadas. 
tierra son mayores que las de Japón e India juntas, aunque ciertamente su marina de guerra es menor. ${ }^{16}$ La tasa de crecimiento anual del presupuesto militar es, según datos oficiales, de $20 \%$. Esto todavía no es un indicio de que China sea el poder militar más efectivo en la región Asia-Pacífico, pues no rebasa cualitativamente el potencial militar de Japón o de Rusia y mucho menos el de los EEUU, que por el momento se mantienen como los garantes de la seguridad en la región de Asia que colinda con el Pacífico.

2. En su creciente presencia internacional, China se esfuerza por evitar casi todo resabio agresivo. Las anteriores rivalidades y enemistades con el grupo ASEAN han sido sustituidas por la colaboración china en diversos ámbitos. Por ejemplo, en la política de seguridad del "ASEAN Regional Forum", en la entrada de China al "Treaty of Amity and Cooperation" de la ASEAN, y en el tratado de libre comercio entre ambas que actualmente se está gestando. Este cambio en la política exterior de China se advierte además en su disponibilidad para dialogar y negociar sobre los puntos de conflicto del Mar del Sur y en general sobre todas las cuestiones marítimas objeto de controversia. El cambio de actitud de China se observa también en las iniciativas conjuntas, como las del grupo "ASEAN + 3", en su notable flexibilidad respecto a la realización de una "Asian Summit", en las relaciones de cooperación con Rusia e India y, no por último, en las relaciones con los EEUU. Se podría continuar con esta lista, pero, ¿esto es suficiente para hablar de un siglo chino o uno de Asia-Pacífico?, ¿se puede hablar ya de la disolución de la primacía de los EEUU?

\section{Dudas sobre la continuidad del siglo norteamericano}

Ya desde hace tiempo, la penetración global de los Estados Unidos en casi todo el planeta ha ido acompañada de una crítica mundial, a veces incluso de aversión, al dominio norteamericano en la política y la cultura ${ }^{17}$ así como

16. Para comparar datos referentes a los años 2004/2005 véase Welt Trends 53, invierno 2006/2007, 102 Fuerzas armadas.

17. Alemania occidental es una excepción, pues en medio del escepticismo que aquí también se desarrolló respecto a los EEUU, nunca se pudieron olvidar dos impulsos positivos provenientes de ahí: la forma distinta con la que trataron a la Alemania derrotada después de la iI Guerra Mundial en comparación con el trato dado por las otras potencias vencedoras y el papel constructivo de la administración norteamericana bajo el presidente George Bush Sr. en la reunificación alemana. 
en la economía y las finanzas. En los mismos estadounidenses han surgido dudas sobre la continuidad del liderazgo global norteamericano. Los reparos se sustentan en muy diversos puntos de partida, pero convergen en las dudas respecto a la permanencia de la función directriz de Estados Unidos. Elementos importantes son los siguientes:

La fuerza militar inquebrantable de Estados Unidos — cuyas dimensiones no han podido ser igualadas por ninguna otra potencia - requiere de un aumento de recursos y una ampliación geográfica del complejo militar que con el tiempo no es posible mantener. Desde hace años, el profesor Paul Kennedy de la Universidad de Yale ha analizado el fenómeno del imperial overstretch a través de comparaciones históricas del Imperio español, Francia, Gran Bretaña, la Unión Soviética y los EeUU, entre otros. ${ }^{18}$ Hasta el presente, las reflexiones de Kennedy han sido seguidas con interés en los mismos Estados Unidos y han sido aplicadas a la crítica de las acciones políticas y geoestratégicas de Washington. Las implicaciones en el exterior son evidentes. Después de la implosión de la Unión Soviética, los EEUU se convirtieron en un superpower global, en quien recayó la tarea de fungir como estabilizador y árbitro en casi todos los ámbitos del sistema internacional. "Containment and expansion" fue el nombre de las estrategias aplicadas. ${ }^{19}$ La tendencia hacia ellas se remonta hasta el siglo XIX. Del imperialismo temprano de Washington se desarrollaron rasgos casi psicóticos, que bajo el presidente Bush Jr. se articularon en delirios persecutorios. Éstos se manifestaron especialmente en los momentos en que Estados Unidos declaraba a otros sistemas políticos y económicos como "los reinos del mal" y casi al mismo tiempo se sentían vulnerables ante el terrorismo internacional.

La seguridad nacional se convirtió definitivamente en la doctrina de Washington, sobre todo después de los ataques terroristas del 11 de septiembre. Aquí surgió una contradicción respecto a los principios de acción de los EEUU que afectó al mundo entero. Si después de la II Guerra Mundial se trabajó constructivamente en un nuevo orden con el establecimiento de instituciones financieras y económicas y se construyó un sistema de alianzas militares basado en el multilateralismo, ahora se toman decisiones que llevan a un unilateralismo que no encuentra aceptación en ningún lado.

18. Véase Paul Kennedy, The Rise and Fall of the Great Powers. Economic Change and Military Conflict from 1500 to 2000, Glasgow, 1988.

19. Véase Stell, Ronald, Temptations of a Superpower, Cambridge, Mass., 1995, p. 22. 
"Containment and expansion" tuvieron además otros efectos: 1. La intensificación del pensamiento estratégico en categorías de esferas de influencia y 2. Una política de contención orientada a Rusia, Asia musulmana y China, que bajo Bush Jr. asumió rasgos fuera de una racionalidad política. Cada vez con mayor fuerza, Estados Unidos acentuó la construcción de un balance internacional, que ellos mismos deseaban presidir como facilitadores. Después del cambio de presidente en enero de 2009, parece que Barak Obama, apoyado por su secretaria de estado Hillary Clinton, hará modificaciones o retirará algunas medidas en estos ámbitos.

También el problema del financiamiento se ha vuelto gravoso. Dejemos de lado la actual crisis financiera y económica y fijemos nuestra atención en un hecho que se perfila desde hace años: no es posible sostener el imperial overstretch norteamericano con el presupuesto, con el balance de exportaciones e importaciones y con la situación económica general del país. Sobre esto se discute desde hace años en Washington. Significativamente, militares de alto rango han estado en repetidas ocasiones del lado de los críticos. Estados Unidos es el país más endeudado del mundo. El déficit de la balanza de pagos fue en 2007 de 800 mil millones de dólares, o sea, $7 \%$ del producto social bruto del país. ${ }^{20}$ Actualmente es más alto y no se observa ninguna cifra significativa de ahorro interno. ${ }^{21} \mathrm{El}$ alto grado de consumo es financiado por préstamos e inversiones del exterior, lo que resultó en parte por el largo tiempo en que el dólar fue la principal divisa del mundo, de modo que China y algunos países pequeños como Dubai se convirtieron en los mayores acreedores de los EEUU. Finalmente las interminables intervenciones militares y las guerras - actualmente Irak y Afganistán - , son cofinanciadas, de menos indirectamente, por acreedores extranjeros.

Tampoco es posible que la versión anglosajona de un capitalismo sin control o neoliberal se mantenga. Aquí dejamos abierta la pregunta, si este capitalismo se puede reformar radicalmente, por ejemplo, en el sentido de una economía social de mercado. La pérdida de prestigio del modelo de economía anglosajona es tan evidente que la función ejemplar que ejercían los estadounidenses apenas tiene vigencia. En todo el mundo, inclusive dentro

20. Zakaria, Fareed, The Post-American World, Londres, 2008, p. 200.

21. Ciertamente Zakaria relativiza la cuota de ahorro, pues según su opinión se deberían incluir los gastos en educación, investigación y desarrollo etc. y así se llega a un balance más positivo (Ibídem, 2001). 
de los EEUU, se ven las consecuencias sociales del modelo orientado a las necesidades individuales y la especulación: a pesar del crecimiento económico, entre los norteamericanos existe una fuerte división social entre un número cada vez mayor de excluidos y discriminados y una indignante capa de ricos. Esto está unido a un drástico déficit social que apenas puede ser comparado con algún otro en el mundo occidental. La clase media americana, el sostén social del país en los años posteriores a la II Guerra Mundial, está desapareciendo. El sistema de salud está extremadamente desequilibrado. Se registran 33 millones de norteamericanos analfabetas. Zonas completas de las grandes ciudades norteamericanas así como muchas ciudades intermedias se asemejan a regiones del tercer mundo. Un porcentaje proporcionalmente mayor que en otros países vive en las cárceles... "Y al igual que en Latinoamérica - como escribió Ronald Stell hace algunos años - una elite acaudalada se esconde detrás de fortificaciones y fuerzas de seguridad. Fuera de estos muros, las filas crecientes de pobres sin educación se vuelven más violentas y peligrosas". ${ }^{22}$

Tampoco el sistema político puede ser considerado como sano. La Norteamérica de la declaración de la Independencia se encuentra junto a la Francia revolucionaria y al Reino Unido en la cuna de la democracia moderna. Pero la contribución norteamericana a su carácter ejemplar es menos convincente ahora que en el pasado. El país nunca ha sido un ejemplo de igualdad social y política. Una marcada oligarquización de la política, el despojo de privilegios a las minorías, la dependencia paralizante de intereses económicos egocéntricos, la manipulación creciente de la opinión pública por los medios y el elevado control sobre la competencia democrática erosionan la idea de un orden norteamericano de checks and balances sistémicos, desaniman a los ciudadanos y empujan a capas enteras a la marginación y la apatía. Si bien Estados Unidos es un país mucho más libre que China, Rusia o Arabia Saudita, han perdido su fuerza global de atracción, porque la esencia del pasado, orientada a la libertad y al republicanismo, ha perdido peso.

Existe la tentación de atribuir muchos de estos puntos negativos al ex-presidente George W. Bush y a su administración. Barack Obama, en su discurso inaugural el 20 de enero de este año, hizo eco de esta crítica. Sin embargo, la pérdida de rango de los EEUU se debe primeramente a una tendencia sistémica que se observa ya desde hace tiempo. Entre los autores que la han advertido se encuentra A. F. K. Organski (1968), posteriormente Chalmers

22. Steel, op. cit., p. 23. 
Johnson con su libro Ein Imperium zerfällt (Un imperio se derrumba), que lleva el significativo subtítulo Wann endet das Amerikanische Jahrhundert? (¿Cuándo termina el siglo americano?), ${ }^{23}$ así como otro libro de Johnson que lleva el nombre de la diosa de la furia justa: Nemesis. The Last Days of the American Republic, ${ }^{24}$ y muchos otros.

Como era de esperarse, también hay quienes sostienen la opinión contraria, por ejemplo el artículo de Niall Ferguson ${ }^{25}$ aparecido en el periódico Die Welt, del 22 de octubre de 2008, con el título Das amerikanische Jahrhundert ist noch nicht zu Ende (El siglo americano todavía no llega a su fin). Su principal argumento es que los Estados Unidos ya han superado más de una crisis, es decir, un contenido optimismo, que también se escucha en Obama al referirse a la oportunidad de revitalizar los valores de los fundadores norteamericanos. El profesor Robert J. Lieber de la Universidad de Georgetown subraya la esencia del poder de los EEUU que todavía se conserva y contiene muchas capas. ${ }^{26}$ Otros señalamientos positivos son aquéllos que se remiten a una dinámica inherente a la sociedad norteamericana que le concede al país una considerable flexibilidad y fuerza de innovación en caso de que la cúpula política y el ámbito gubernamental no correspondan a las expectativas de una good governance.

En un artículo como éste no es posible conciliar de forma convincente tales posiciones, pues habría que hacer profecías que difícilmente podrán realizarse. De cualquier manera el problema de la situación norteamericana se puede describir en algunos puntos:

1. Tanto internamente como en el ámbito internacional, se ha perdido la confianza en los Estados Unidos en aquellos campos anteriormente mencionados. Igualmente, los estadounidenses no superan la frustración causada al ver que sus propias ideas de democracia y orden económico ya no son consideradas globalmente como modelos. ${ }^{27}$ En tal contexto, no pocos analistas hablan de un engaño intencional o de menos de un autoengaño en la actuación norteamericana nacional e internacional. Pero las causas de esta perspectiva política son más profundas: si bajo

23. Munich, 2000.

24. Nueva York, 2006.

25. Ferguson es un británico que enseña en Harvard.

26. Véase Lieber Robert J., "Falling Upwards. Declinism: The Box Set”, World Affairs, 2008 (verano), pp. 48-56.

27. Zakaria, The Post-American World, op. cit., p. 34. 
un signo religioso-ideológico uno se entiende a sí mismo como God's own country y a ello se vincula cada vez con mayor fuerza la dinámica de un imperialismo tanto geopolítico y económico como militar, entonces debe ser difícil comprender otras culturas, otros intereses y otras ideas del mundo social, político y económico. Ya no es posible un diálogo serio con otros pueblos, con otros políticos o con otros científicos, mucho menos aceptar alternativas que no caben en la propia visión del mundo. Esto es, por cierto, una de las causas de la preferencia americana por el unilateralismo o bilateralismo en lugar de un multi-lateralismo basado en la cooperación.

2. Cuando Obama subraya "el regreso a nuestra historia completa", manifiesta el deseo de renovar profundamente un modelo en crisis pero en principio digno de defenderse. Sin embargo, la pregunta es, ¿̇se puede sostener este modelo en un mundo que tecnológicamente está cada vez más conectado en muchos ámbitos de la comunicación y que entendemos como globalización y en el que países y sociedades completas luchan por conservar su cultura e identidad? ¿Se equivoca uno realmente cuando expresa la impresión de que los Estados Unidos determinan cada vez menos la globalización y que, por el contrario, más bien están expuestos a ella? Además, en este exceptionalism han intervenido amplias elites de otros países como actores que ejecutan y participan en la conformación del orden. Actualmente han cambiado de posición y reclaman independencia. ¿Puede el nuevo gobierno norteamericano revertir esto último, aun cuando comprenda y quiera transformar las cosas?

3. Esto nos conduce al siguiente punto que precisamente en nuestro tiempo llama la atención: "El mundo del siglo XXI parece ser tan complejo e impredecible" que el mismo Stephen Hawking habla de un caos mundial que ha tomado dimensiones políticas, sociales y ecológicas, y cuya superación significa nada menos que el futuro de la humanidad. ${ }^{28}$

4. Esto último está lejos de reclamar una responsabilidad única y exclusiva de los EEUU. Aquí ha surgido un desafío que solamente se puede afrontar mediante la cooperación global, que necesita capacidades y valores distintos a los requeridos por el cientificismo estadounidense y sus fábricas de pensamiento, por las seudo-investigaciones con sus métodos y research strategies sin contenido y por el eterno positivismo de las estadísticas

28. Véase Khannna, Der Kampf um die Zweite Welt, op. cit., p. 502. 
casi vacías. Respecto a esto, Hans Morgenthau sostiene la opinión de que "el cientificismo con su dominio técnico de la naturaleza sin vida ha enriquecido a la humanidad, pero en la búsqueda de una respuesta al enigma del mundo y su existencia la ha dejado empobrecida". ${ }^{29}$

5. Esto nos conduce directamente al tema especial de este artículo. El mundo internacional de los Fords, Carters, los dos Bushs, Clintons y Obamas ha cambiado en sus escenarios cualitativos. Han surgido o están surgiendo nuevos poderes, que, para decirlo en términos de Fareed Zakaria, hacen pensar en un postamerican world. Si los Estados Unidos desean conservar un papel sobresaliente, si quieren comprender los cambios en el mundo ${ }^{30} \mathrm{o}$ si, como sostiene Parag Khanna, trabajan en un ordenamiento conceptual y político-práctico de los Estados Unidos en un "segundo mundo", será necesario un cambio en su pensamiento. El ocuparse de un siglo asiático o chino es entonces una dirección para el pensamiento, pero no la única. Khanna propone otra: "Por primera vez en la historia existe un mundo multipolar y multicultural con tres superpotencias muy diferentes", es decir, los Estados Unidos, Europa y China. ${ }^{31}$ Se pueden tener algunas dudas respecto a esta triada. Pero aquí se señala que los problemas de un siglo chino del Pacífico asiático en relación con los Estados Unidos, no puede ser discutido sin incluir a Europa.

\section{Asia y su autoconciencia}

Hubo y hay una larga serie de factores que han conducido a la tendencia evidente de una asiatización de Asia: impulsos intelectuales que pertenecen a los antecedentes del debate asiático sobre valores, principios de cooperación así como una autoconciencia que despierta o ha despertado a partir de los éxitos alcanzados. ${ }^{32}$ Esta asiatización no deja de lado al Japón que se ha modernizado

29. Ahí citado. En una dirección similar y con vista a la situación alemana de las ciencias políticas lo trata el autor de este artículo: "Droht der Politikwissenschaft ein massiver Relevanzverlust? Eine Erfolgsgeschichte in den Grenzen von Spannungspunkten”, Werner Patzeit, e.o. (editor), Wissenschaft und politische Bildung im Dienste des Gemeinwohls. Libro homenaje para Heinrich Oberreuter con motivo de sus 65 años, Wiesbaden, 2007, pp. 27-42.

30. Véase Zakaria, Fareed, "The Future of American Power. How American Can Survive the Rise of the Rest", Foreign Affairs 14.11.2008 (copia en Internet).

31. Khannna, Der Kampf um die Zweite Welt, op. cit., pp. 494 y 478.

32. Véase Mols, Manfred, "Is there an Asianisation of Asia? The New Millenium in Asia and the Identity Debate", Panorama (Singapur) 1/2004, pp. 57-64. 
parcialmente. ${ }^{33}$ Entre los pioneros de este desarrollo se encuentra el japonés Kazuko Okakura, quien al inicio del siglo xx presentó un libro digno de llamar la atención, y que en su traducción inglesa lleva el título The Ideals of the East. ${ }^{34}$ Okakura alude ahí a la unidad de Asia con la frase frecuentemente citada "Asia is one".$^{35}$ Los puntos de la argumentación de Okakura todavía son válidos: la idea de la unidad de Asia fue impulsada por el colonialismo y la humillación, por lo que trata de encontrar una forma propia de modernización. Estas reflexiones influyeron en el bengalí Rabindranath Tagore y otros intelectuales y políticos asiáticos. Sun Yat-sen retomó la posición de un "pan-asianismo" como frontera ante un Occidente materialista e imperialista. ${ }^{36}$ Tampoco a Jawaharlal Nehru le eran extrañas estas ideas. La Asian Relations Conference en Delhi, a la que convocó en 1947, se celebró significativamente antes de la independencia india. Éste y otros impulsos no han provocado hasta ahora la unidad de Asia, pero tienen un efecto en los círculos intelectuales del presente, no como un gran fuego, pero sí como una llama que en tiempos propicios puede expandirse.

Esto se manifestó por ejemplo en el primer congreso de la recién fundada asociación de politólogos, APISA ${ }^{37}$ en noviembre de 2003 en Singapur, en el que algunos temas eran inconfundiblemente asiáticos. Hay que señalar además que precisamente en Japón, en el curso de su orientación a Occidente y un reencuentro casi simultáneo con su propia historia y cultura, se reflexionó sobre estas cosas, especialmente sobre la relación tirante entre la reorientación pro-asiática y una especie de papel mediador con Occidente..$^{38}$ Lisette Gebhardt señala que algo de esto será retomado a favor del propio pensamiento tradicional japonés, y habla incluso de una "colonialización del alma japonesa". ${ }^{9}$

En el curso del desarrollo japonés y la modernización exitosa de los países tigres surgieron dos impulsos fundamentales. Shintaro Ishihara, más tarde gobernador de la prefectura de Tokio, presentó en 1992 un libro con el desa-

33. Véase Derichs, Claudia, "Is Japan on its Way to Being Re-Asianised? -The Changed Determinants of the Political Decision-Making Process", Asiatische Studien. Ëtudes Asiatiques, LYI, 1997, pp. 49-70.

34. Londres, 1903.

35. Ibídem, p. 32.

36. Véase Emmott: Rivals, op. cit., p. 30.

37. Asian Political and International Studies Association.

38. Con mayor detalle en Claudia Derichs, op. cit.

39. Véase Gebhardt, Lisette, "The Sowers of the Asian Seed: Nagakami Kenji", Asiatische Studien, ibídem, pp. 124-147. 
fiante título: Nosotros somos la potencia mundial. ¿Por qué el futuro le pertenece a Japón $?^{40}$ Ahí como en otras publicaciones, Ishihara argumenta de manera nacionalista, pero aporta dos puntos de vista que en Asia han mantenido su peso: se está consciente de los avances en la modernización —el potencial tecnológico alcanzado no es el menor-, pero a ello se une inmediatamente el orgullo y el tesoro de las experiencias de una historia milenaria. No sorprende entonces que el jefe de gobierno malasio Mahathir Mohammad, con su llamado al Look East, viera en esta mezcla japonesa de historia exitosa y proclamación de la identidad cultural un modelo de orientación para el grupo de países del sureste asiático. Casi se sobreentiende que para Mahathir y para Ishihara el Occidente, especialmente los Estados Unidos, son el contraste y al mismo tiempo los "federadores" 41 externos de la cooperación interna asiática.

Otro buen ejemplo de la conciencia que ha recobrado Asia de sí misma lo ofrecen los trabajos del ex-embajador de Singapur en las Naciones Unidas, Kishore Mahbubani. El experimentado diplomático y ahora decano en la Lee Kuan Yew School of Public Policy de la Universidad Nacional de Singapur publicó hace una década un compendio de artículos con el título Can Asians Think?, ${ }^{42}$ con una introducción que lleva el mismo título. Según su opinión, ya no es posible aceptar la fórmula West against the Rest, pero para que Asia pueda hacerse presente en los ámbitos internacionales debe involucrarse con mayor energía en los proyectos y el desarrollo de innovaciones de todo tipo. En Mahbubani se observa un acento diferente a otros trabajos asiáticos sobre la relación Asia-Occidente, pues no pretende demostrar en primera línea una superioridad asiática, ${ }^{43}$ sino una igualdad de estatus con Occidente. Según Mahbubani, los asiáticos deben esforzarse activamente por lograr esta equidad, aprendiendo, entre otros, de Occidente. Mahbubani no pasa por alto que efectivamente ocurre un desplazamiento del poder en la esfera global a favor de los asiáticos.

40. Publicado en Alemania en 1992 y en inglés en 1991. El título inglés es menos pretencioso que el alemán: The Japan that can say no.

41. Sobre el concepto de federadores externos en los procesos de cooperación e integración, véase Mols, Manfred, Integration und Kooperation in zwei Kontinenten. Das Streben nach Einheit in Lateinamerika und in Südostasien, Stuttgart, 1996, pp. 36 y ss, pp. 396 y ss y passim.

42. Singapur, 1998.

43. Típico por ejemplo Kishore Mahbubani, The New Asian Hemisphere. The Irresistible Shift of Global Power to the East, Nueva York, 2008. 
Es evidente que China e India, del lado asiático, tienen un papel decisivo. Pero esto no significa el inicio inmediato de un siglo asiático, sino, por ahora, de poner en marcha un proceso de igualación global. El siguiente "paso de la historia mundial será determinado por la forma en que Occidente reaccione a la gran marcha de Asia en la globalización". ${ }^{44}$ Hay que tener presente que Occidente igualmente tiene que aprender a aceptar la transición de la política mundial. No es posible que $12 \%$ de la población mundial siga dominando. Por lo tanto, Occidente es parte del problema de la modernización global y también parte de su solución. ${ }^{45}$ Según Mahbubani en su libro más reciente, ${ }^{46}$ de esto dependerá el curso de la historia mundial. Occidente debe tener presente que el dominio del mundo en los últimos dos siglos fueron una excepción en la impresionante historia asiática en los últimos dos mil años. Esto no excluye que los asiáticos deban atender los "fundamentos de la sabiduría occidental" en su dinámica como guía de la modernización, es decir, la democracia, el Estado de derecho y la justicia social, ${ }^{48}$ y naturalmente también el pragmatismo, el impulso a la innovación, la investigación y el desarrollo y muchas otras cosas más. Esto debe ocurrir en un doble proceso paralelo de desoccidentalización y revitalización de la historia asiática, lo que actualmente se observa en muchos lugares de Asia, por ejemplo, en China. Finalmente, la visión de Mahbubani termina en una fusión de valores occidentales y asiáticos, de formas de comportamiento y de otros logros civilizatorios.

Otra cuestión es si las elites occidentales en la política, la economía y la ciencia en los EEUU y en Europa podrán desarrollar la sensibilidad necesaria y buscar posibles consecuencias. En la discusión sobre los desplazamientos del poder, Mahbubani y Khanna muestran puntos coincidentes. Para éste último todavía no es seguro que Oriente despoje de su rango a Occidente. La decisión dependerá de la medida en que uno y otro logren hacer de su lado al llamado segundo mundo (o sea el gran número de Estados que no pertenecen a las actuales superpotencias ni tampoco al tercer mundo, pero no fueron ni son parte del primer mundo). Este proceso, según Khanna, se encuentra en pleno desarrollo. "En todas partes se puede ver que la tierra se americaniza, se

44. Ibídem, p. 36.

45. Ibídem, p. 8 y ss.

46. Ibídem, p. 26.

47. Ibídem, p. 50.

48. Ibídem, p. 236. 
europeiza y se siniza al mismo tiempo" ${ }^{49}$ No se trata de ofrecer un pronóstico sobre un posible resultado, sino de señalar que ocurre un enfrentamiento por posiciones de poder entre los Estados y las sociedades. Al respecto, Khanna menciona diferentes estrategias: los tres centros de poder mencionados por él, Estados Unidos, Europa, Asia o China, recurren a diversas modalidades para asegurarse de aliados en el segundo mundo. Los Estados Unidos apuestan por las coaliciones, Europa por el consenso y China por las consultas, ${ }^{50}$ los primeros por uniones que son útiles a sus propios intereses y por las instituciones internacionales, los segundos por convenios o arreglos y los chinos finalmente por el diálogo y los acuerdos recíprocos.

Aquí ya no seguimos la cuestión, si la situación en la política mundial es realmente tan abierta como se supone. Debemos regresar al tema de la autoconciencia de Asia, que en los años noventa recibió un fuerte impulso del debate sobre los valores. Claudia Derichs y el autor formularon una interpretación de este debate en una publicación conjunta en 1995 con el título “El final de la historia o un choque entre las civilizaciones?"

El debate sobre los valores, en el que participaron políticos de alto nivel e intelectuales de diferentes naciones de Asia oriental (Lee Kuan Yew, Mahathir Mohammad, Anwar Ibrahim, Yasuhiro Nakasone, Kim Dae Jung, Ham Chaibong, Pushpa Thambipillai, entre otros) ha sido poco entendido en Occidente. No se trató de reservas ante el paso de un mundo preindustrial a uno moderno, sino del reencuentro con una identidad asiática en tiempos de rápidas transformaciones. A partir de la propia tradición se intentó reflexionar sobre el problema de las relaciones entre la comunidad y el individuo. Se pugna por una actualización sustentable de un modelo asiático de valores y comportamientos en la era de la globalización. En este sentido el ex-presidente Nakasone afirmó: "No creo que el tipo norteamericano o británico de economía de mercado capitalista sea el único modelo válido". ${ }^{52}$

El intento de Asia por asegurarse de su identidad se deriva de otro elemento, es decir, del crecimiento de organizaciones conjuntas. Se trata de foros de cooperación que buscan fomentar la ayuda recíproca o, de menos,

49. Khanna, Der Kampf um die Zweite Welt, op. cit., p. 18.

50. Casi textualmente, Ibídem, p. 20.

51. Mols, Manfred y Claudia Derichs, "Das Ende der Geschichte oder ein Zusammenprall der Zivilisationen?”,Zeitschrift für Politik, núm. 42, cuaderno 3, 1995 pp. 225-249.

52. Yasuhiro Nakasone, "Oriental Mind and Occidental Spirit", Asia Pacific Review 1/1, 1994, p. 10. 
el fortalecimiento de las relaciones internacionales. Desde hace décadas, se han desarrollado paulatinamente formas de cooperación, que si bien están lejos de ser lo que en Europa se llama integración, han hecho posible un acercamiento entre los países asiáticos. Estas formas tienen un amplio potencial de desarrollo. Las conversaciones intergubernamentales que se llevan a cabo regularmente son parte de ellas. Han surgido redes transnacionales, sobre todo en los niveles económicos. Se han efectuado conversaciones sobre cuestiones de seguridad que anteriormente nadie hubiera pensado que serían posibles. Éstas y otras cosas han permitido madurar un sentimiento de identidad regional. Además, han logrado efectuar foros de conversaciones con impacto tanto en el contexto regional como internacional, y que subrayan la voluntad de ascenso de Asia oriental en el mundo globalizado.

Para institucionalizar un poco todo ello, la Asociación de Naciones del Sudeste Asiático (ASEAN), fundada en 1965, debía convertirse en un pilar fundamental. A pesar de las difíciles condiciones internacionales debidas a reformas permanentes y ampliaciones institucionales, la Asociación no sólo logró mantenerse y expandirse poco a poco a todo el sureste asiático, también consiguió organizar un programa de diálogo internacional, el ASEAN Regional Forum, en 1993. En el foro participan importantes países de todo el mundo, como los Estados Unidos, Europa, India, China, Japón y Rusia, y se discuten principalmente cuestiones de orden y seguridad. Otro logro sustancial de estos procesos de cooperación es su contribución al fortalecimiento de las relaciones económicas y políticas entre los países del sureste asiático así como con sus vecinos más importantes, entre ellos destacan el "Proceso ASEAN + 1", con la República Popular China, y el "Proceso ASEAN + 3 (ASEAN + China + Japón+ Corea del Sur). Con Europa se realiza una cumbre con regularidad. Y con Latinoamérica se intentó algo similar. ${ }^{53}$ En el año 2005 en Kuala Lumpur, se convocó a un "East Asian Summit", en la que participan también India, Australia y Nueva Zelanda, de modo que ya se habla de un "Proceso ASEAN + 6".

Otra característica de la internacionalización es la pertenencia de los países desarrollados miembros de la ASEAN, los demás Estados asiáticos y norteamericanos y en parte también los países latinoamericanos contiguos al Pacífico a la "Asia Pacific Economic Cooperation" (APEC). Si bien esta organización no ha dejado de ser un foro de diálogo, gracias a la iniciativa Seattle del presidente Clinton en 1993 se realizan encuentros regulares entre los

53. Que no funciona de manera convincente debido a la parte latinoamericana. 
jefes de Estado y de gobierno así como conferencias y conversaciones en los niveles de ministros y directores de gobierno de los 21 miembros, lo que significa la celebración de cumbres anuales de toda la región del Pacífico. Aun cuando mucho de lo que ocurre en estas conversaciones y eventos son sólo intentos por lograr un mayor equilibrio sin carácter vinculante, en el conjunto de las relaciones institucionales se manifiesta un proceso de fermentación que contribuye evidentemente al fortalecimiento de la autoconciencia en la región Asia-Pacífico.

En este proceso es discutible de qué lado provienen los impulsos decisivos. Por un lado, China juega un papel clave cada vez más claro en el desarrollo de Asia oriental, ${ }^{54}$ por otro, Japón en estas cuestiones no está tan cansado como a menudo se señala y sigue sus propios intereses en la región del este asiático. Por otro lado más, el grupo ASEAN tiene un derecho constitutivo para participar en los esfuerzos por lograr el crecimiento conjunto de Asia oriental, o sea, Asia-Pacífico. ${ }^{55}$ De cualquier manera, mucho ocurre formalmente dentro de los marcos de la ASEAN, lo que le concede a este grupo la ventaja de decidir sobre los temas de las conversaciones y negociaciones. Al grupo ASEAN le favorece que las luchas por el poder en el oriente de Asia no representa ningún factor de irritación. Para China, Japón y ahora también India, Australia y Nueva Zelanda (en los marcos de la East Asian Summit) existe la ventaja de poder mantenerse al margen oficialmente y sumarse diplomáticamente a un desarrollo. Pues si articularan intereses propios al punto extremo en torno a este desarrollo ocasionarían serios conflictos. ${ }^{56}$

Por lo demás, hay que coincidir con Hanns Günter Hilpert: "La cooperación multilateral de Asia oriental tiene como condición implícita la vigencia de los acuerdos bilaterales de seguridad con la superpotencia Estados Unidos y la fuerza estabilizadora de la Pax Americana". ${ }^{57}$ Con ello, los Estados Unidos juegan en este proceso de cooperación de Asia oriental el papel doble de "federador". Los sentimientos anti-occidentales abiertos, latentes o parciales de Asia oriental, y

54. Véase Günter Hilpert, “China als Motor der asiatischen Integration?”, Asien, núm. 102, enero, 2007, pp. 47-62.

55. Véase Dosch, Jörn, The changing dynamics of Southeast Asian politics, Boulder y Londres, 2007.

56. Conversaciones del autor en las divisiones que se ocupan de Asia en los respectivos ministerios del exterior en los tres países en los años de 2003 a 2006.

57. Hilpert, op. cit., p. 61. Sobre los conflictos abiertos y a menudo subliminales por el liderazgo en el oriente de Asia véase Nabers, Dirk, "China, Japan and the Quest for Leadership in East Asia”, GIGA Working Papers, núm. 67, febrero, 2008. 
junto a ellos los intentos por encontrarse culturalmente y, si es posible, también en el orden político, son el elemento federativo externo. El otro es la garantía de un escudo de seguridad que hasta al momento ha funcionado.

\section{Las fronteras del desafío del Pacífico asiático}

Ante "la gran marcha asiática a la modernidad" (Mahbubani), Asia-Pacífico se desarrollará como una potencia global que le permitirá cada vez menos a Occidente seguir tras su filosofía de business as usual. Esto limita la influencia y el amplio efecto del siglo norteamericano, pero afecta también a Occidente en su conjunto y, por consiguiente, a los europeos en su papel global. No puede pasar inadvertido el deslizamiento del poder político y económico del mundo hacia Oriente. Insistir en la firme supremacía de Occidente ante la creciente participación de Asia en la comunidad internacional de Estados así como en la sociedad, la cultura y la población mundial, etc., no sería ni deseable ni aceptable. El siglo norteamericano se ha topado con los límites de su aceptación, pero su rápida sustitución es también incierta. ¿Por qué no es posible dejar ocupar a Asia el lugar de Estados Unidos sin reserva alguna? La respuesta es sencilla: porque bajo los puntos de vista de un cambio de siglo, Asia no convence o todavía no logra convencer. Para ello existen varias razones.

1. El mundo moderno globalizado y globalizante vive de los modelos de civilización que disponen precisamente del rango de soft power, es decir, de patrones ejemplares convincentes que estimulan una imitación parcial o completa en los ámbitos centrales de la vida. Asia no ofrece ningún perfil capaz de ser imitado. Asia es una región del mundo con una multiplicidad y diversidad de órdenes políticos, culturas, sistemas religiosos y políticos, experiencias históricas individuales, con distintas estructuras sociales, formas económicas, niveles de desarrollo, formas de vida y también - no menos importante - con una occidentalidad parcialmente alcanzada, de modo que no pudo surgir un patrón ejemplar ni en la región misma ni en la escala global.

De ahí - escribe Peter Katzenstein - que tengamos que ver con una "verdadera forma híbrida de regionalismo", ${ }^{8}$ o sea, con algo conjuntado y mezclado proveniente de diferentes fuerzas y momentos. Entre los factores

58. Katzenstein, Peter J., "East Asia -Beyond Japan”, en Katzenstein, Peter J. y Takashi Shiraishi, Beyond Japan. The Dynamics of East Asian Regionalism, Ithaca y Londres, 2006, pp. 1-36, aquí p. 2. 
genéticos de este regionalismo se encuentran un fragmento de japonización, un fragmento de americanización, un fragmento de sinización, un fragmento de europeización, un fragmento de intentos democráticos y, de menos, un fragmento de good governance propia. Detrás de ello se encuentra la herencia del development state, la gran influencia de Occidente en la nueva época colonial y en el siglo xx, el ascenso inesperado de China, el ejemplo de la integración europea, el intento que no pocos países de Asia emprenden para no sacrificar el rumbo político ante el pluralismo social, la negativa a considerar la democracia representativa como la única condición posible para la economía de mercado, etcétera.

Por ello, no existe ningún modelo asiático unitario y las ideas de un soft power asiático desaparecen, toda vez que un soft power no puede renunciar al hard power que sigue actuando en la política mundial en la construcción de estructuras. Se podía pensar, por ejemplo, en el poder de la economía o en el de la tecnología, o bien, en sistemas gubernamentales efectivos. En relación a Asia, esto significa que un modelo híbrido o diferentes modelos híbridos no son apropiados para marcar globalmente a un siglo.

2. No está claro quién o qué realmente debe asumir el papel protagónico en Asia por una centuria. Un siglo chino no lograría imponerse a escala mundial, porque China en su perfil general no convence, aun cuando sus debilidades sistémicas no justifican que se usen las expresiones "potencia del caos" o "bluffs" para referirse a su presencia internacional. ${ }^{59}$ Un crecimiento económico que no tiene comparación con ningún país, si bien sorprende al pensamiento de muchos seres humanos y Estados, especialmente en los círculos bancarios, de la economía real y de los profesores de ciencias económicas en una era de economismo casi absoluto, no observa, en su ingenuo parcialismo, la multitud de otros campos importantes de la vida. Esto se manifiesta claramente en las crisis financiera y económica presentes, cuyo lado cultural-psicológico con sus egoísmos individuales pertenece al conjunto de las crisis del mismo modo que la falta de controles efectivos gubernamentales y transgubernamentales que intervengan internacionalmente (a los que se opusieron en Heiligendamm el lado norteamericano y británico).

En el caso de China, el crecimiento de la economía no es ningún argumento serio para el futuro. En su forma actual, por los daños al medio ambiente que

59. Véase Möller, Kay, “Der Beijing Bluff. Chinas Aussenpolitik”, en WeltTrends 53, invierno, 2006/2007, pp. 11-22. 
origina, no se puede sostener durante largo tiempo. Al mismo tiempo, la crisis permite ver que China también es en extremo vulnerable, pues no se puede desarrollar más allá de la capacidad de absorción de los mercados extranjeros. Además, hay que señalar la considerable dependencia tecnológica de las inversiones provenientes del extranjero así como la piratería. Para China, el abastecimiento de energía y de materias primas suficientes es cada vez más difícil. Hasta el presente, China no ha logrado la igualdad social. Cuando en los debates de los medios occidentales se menciona la existencia de 100 a 200 millones de desempleados, se manifiestan una vez más los márgenes de acción del gobierno chino. Hasta ahora, no ha surgido una sociedad y una política de respeto a los derechos humanos y de los ciudadanos. Los aspectos positivos del comportamiento de China en el exterior se vuelven relativos por su indiferencia ante situaciones en que hay que actuar por razones éticas para abastecer masivamente a la población, como en ocasiones ocurre en África y Latinoamérica. A esto se agrega, en el nivel global, lo extraña que parece la cultura china y sus derivaciones modernas, inclusive la dificultad del idioma chino y sus dialectos. Todo esto dificulta el dominio chino, aunque hay que aceptar que el ascenso estratégico de China ya mostraba retrasos y era deseable.

El resto de Asia no reúne las condiciones para construir un perfil propio e influyente. El "development state" japonés, que en su tiempo fue muy exitoso, carece de fuerza de atracción desde hace años. En la política de desarrollo —no solamente económica一, cada país de la ASEAN recorre su propio camino. India en conjunto todavía se encuentra bastante atrasada como para contribuir a un perfil de Asia que funcione como modelo.

3. Con el título de su libro Rivals, Bill Emmott está probablemente tras la pista correcta, en el subtítulo señala que se refiere a la lucha creciente por el poder entre China, India y Japón. "Balance of power" es la cuestión clave del desarrollo interno asiático, pero marca al mismo tiempo las fronteras de su influencia internacional. Hace falta una clara potencia líder. Esto es válido también para China que se encuentra ahora en la posición más adelantada, pero que igualmente encontrará sus límites continentales como fue el caso de Gran Bretaña en el siglo XIX en Europa. ${ }^{60}$ La competencia entre China y Japón ha despertado la creencia en cada uno de estos países o en sus dirigentes políticos de que el futuro les pertenece. Según Emmott, existe un drama

60. Emmott, Rivals, op. cit., p. 10. 
asiático que comprende todo un complejo de amarguras históricas, disputas territoriales no resueltas, puntos conflictivos que en cualquier momento pueden estallar y otras divergencias. La respuesta lógica esperada será un rearme que comprenda también la técnica espacial, lo que por su parte elevará la desconfianza recíproca ya existente. Según Emmott, ese es realmente el drama asiático. ${ }^{61} \mathrm{Si}$ esto es verdad, hay que reconocer que el mundo de un siglo asiático o del Pacífico asiático, en caso de que se llegara a ello, todavía está muy lejos.

Aquí nos topamos de nuevo con la tesis de Parag Khanna sobre el propio ordenamiento de los imperios, inclusive el de los EEUU, en un segundo mundo de renuncia hegemónica y de equidad de todas las potencias desarrolladas. Tal tesis ejerce ciertamente cierta atracción política, pero deja de lado el curso de la historia, pues coloca meros deseos en primera línea e ignora el elevado potencial cultural.

Si son correctos los resultados del grupo de investigadores de la UNESCO dirigido por Helio Jaguaribe, mencionados en el inicio de este artículo, en el sentido de que la civilización del mundo imperante por el momento es una manifestación de la "civilización occidental tardía", entonces no se puede ignorar el papel decisivo de los Estados Unidos. El perfil cultural civilizatorio del mundo presente y del futuro predecible es el resultado conjunto de conformaciones europeas y luego norteamericanas. En el presente, nadie más que Europa y los EeuU se encuentran bajo el desafío de Asia y Asia-Pacífico. Si Europa fracasa, la estafeta de la responsabilidad pasa a los Estados Unidos, quienes, por su parte, pueden ejercer el poder como principio de defensa y de afirmación. Si EEUU y Europa fracasan en su defensa de la occidentalidad, entontes los asiáticos, así como los árabes y africanos buscarán friccionar tutelas y hacer reivindicaciones, lo que hará más imprevisible la situación mundial y ahondará aquel "clashes of civilizations" que señaló hace algunos años Samuel Huntington. Para decirlo lo más claro posible: reside en nosotros, europeos, así como en los estadounidenses dotar a la occidentalidad paradigmática de la vitalidad necesaria o perpetuar por décadas la situación mundial presente con sus potenciales de tensión. En otras palabras, los Estados Unidos deben retroceder claramente un paso y Europa debe arriesgar un claro paso al frente.

Al final de este artículo surgen varias preguntas:

61. Ibídem, p. 307. 
La primera es: ¿qué es lo que los europeos han aportado a la modernidad que se convirtió en la esencia del mundo presente y futuro?

La segunda pregunta es: ¿con vista a la parte norteamericana de la occidentalidad, a qué no debemos renunciar si se piensa en el futuro del planeta?

Tercera pregunta: ¿cómo y bajo qué condiciones es aceptable para el "resto" del mundo esta continuación de la "civilización occidental tardía" o, de menos, una parte sustancial de ella? Pues en estas reflexiones debió quedar claro que no se trata de la sustitución de un siglo norteamericano por el de Asia-Pacífico, o China, o la tríada China, India, Japón, ni por una era semejante a la occidental. Se trata de corregir los errores civilizatorios y políticos y de proponer mejoras a una situación que tomó caminos equivocados y cuya disolución debe llevar ajustes políticos y una relativa igualación en el ámbito del poder, pero no a una mera uniformidad.

\section{El papel provisional de Occidente}

Hay que recordar aquí la frase citada en un principio: la presente civilización del mundo se presenta todavía en las estructuras y normas fundamentales de la civilización occidental. El grupo de la UNESCO ya mencionado eligió el calificativo "tardío", porque no puede negarse que aquello que se erigió en un proceso milenario y debe ser siempre impulsado con sus soportes determinantes - Israel, Grecia y Roma, Italia y Francia, los Países Bajos y el Reino Unido, Alemania y el mundo eslavo, Escandinavia y la península ibérica, los Estados Unidos de América y lo que se articula en Rusia, Australia y Nueva Zelanda-, constituye en sí mismo una red de aculturaciones en un proceso histórico abierto. A ella se añaden manifestaciones significativas del "exterior", como por ejemplo, la influencia de la cultura árabe o hindú, o la disposición de Portugal a incluir modelos orientales en sus diseños de construcción. Tampoco se puede dejar de considerar la influencia indígena en la literatura, el baile, la música y en los mismos hábitos alimenticios. Posiblemente también las ideas occidentales de derechos humanos, justicia internacional, orden económico y la misma teología cristiana se verían más limitadas, más escuetas, sin las influencias culturales provenientes más allá de Europa, la zona del Mediterráneo y América, o mejor dicho, las dos Américas.

En la era de una globalización múltiple, todas estas cosas han alcanzado tal fuerza de penetración que la exclusividad y la exclusión del otro traen consigo una serie de problemas que claramente entorpecen el camino de una 
convivencia pacífica en nuestro planeta. La simple constatación de ello apenas tiene un efecto vinculatorio, por lo que es necesario que se den pasos prácticos y efectivos para superar los actuales cismas globales. En los marcos de un artículo como éste, hay que nombrar finalmente algunas de estas estrategias sobre la base de nuestro tema, es decir, el fin del siglo norteamericano y su posible sustitución por uno del Pacífico asiático.

Coincidimos con la tesis fundamental de Kishore Mahbubani de que en el futuro no puede haber un "resto" tutelado - lo que alude a la clara mayoría de la humanidad-. También Mahbubani no resiste la tentación de hablar abiertamente de un futuro siglo asiático o de que éste ya ha empezado. ${ }^{62}$ Respecto a la pregunta, ¿de dónde deben venir los impulsos para el reemplazo parcial y la transformación? Mahbubani menciona como fuerzas impulsoras a China, el grupo ASEAN, Japón, Corea y el multilateralismo asiático-Pacífico. Pero aquí se sobrevaloran algunas cosas. Pues si se repasan los actores, el resultado es frustrante. No se puede imponer una visión del mundo sinocéntrica ni en Asia $^{63}$ ni en otras partes del mundo. China no ha desarrollado ninguna burguesía mundial ni tampoco — como escribe Ai Weiwei— ${ }^{64}$ ningún sentimiento de responsabilidad global más allá de un centrismo autoritario. Aunque es imposible no percatarse del ascenso de China como global player, es evidente que se trata de un proceso de transformación que no ha concluido y que su resultado es, por lo tanto, incierto. ${ }^{65}$ No se pueden ignorar los conflictos entre las nacionalidades, que no pueden ser solucionados por "una concepción patriarcal del Estado que prescribe las tradiciones de un pasado feudal", ${ }^{6}$ toda vez que Pekín sólo de forma muy condicionada puede controlar todo el Estado en sus segmentos inferiores y en las provincias lejanas.

El grupo ASEAN es en sí muy heterogéneo y, con excepción de Singapur, subdesarrollado, además es políticamente irrelevante para conformar de manera importante lo que Mahbubani denomina como "tectonic shift". Tampoco Japón puede ser considerado como fuerza impulsora del reacomodo global,

62. Mahbubani, Kishore, "Welcome to the Asian Century", Current History, mayo, 2008, pp. 195200.

63. Véase Christoph Müller-Hofstede, "Die Geschichte der chinesisch-westlichen Beziehungen: ein Überblick", Landeszentrale für politische Bildung Baden Würtemberg (editor), Die Volksrepublik China, Stuttgart, 3/4, 2008, pp. 172 -179.

64. Weiwei, Ai, "Ein Monster in Trümmern", Die Zeit, núm. 14, 2009, p. 49.

65. Véase Müller-Hofstede, ibídem, pp. 180-185.

66. Heberer, Thomas, "Nationalitätsprobleme in China und die Tibet-Frage", Der Bürger im Staat, ibídem. pp. 203-209. 
pues apenas existe un soft power con influencia mundial. No hay que compartir la opinión de quienes acusan a Japón de la marginalización internacional, la demanda excesiva y la decadencia del sistema político, ${ }^{67}$ pues Japón es por el momento la principal potencia económica y tecnológica de Asia. ${ }^{68}$ En 2007, con $9 \%$ del ingreso mundial, produjo más que China e India juntas. Además, el país siempre interviene constructivamente en la región del este y sureste asiático y sus múltiples acuerdos. ${ }^{69}$ Sin embargo, no es posible una amplia "pax nipponica" por dos razones: primero, Japón, con excepción de sus acciones contra los Estados Unidos y China en la guerra del Pacífico, nunca ha ejercido un papel importante en la política mundial. Y, segundo, todavía existe una pesada carga histórica proveniente de la primera mitad del siglo XX, que Japón nunca ha sabido desmontar. Corea, o sea, Corea del Sur, no sería ejemplo de un posicionamiento internacional, pues por el momento debe solucionar el problema de su división, y por su geografía estratégica siempre estará entre China y Japón. El recuento de Mahbubani engaña, pues sugiere una convergencia de Asia oriental que, a pesar del crecimiento conjunto, no existe.

Quedan entonces todavía los dos global players más influyentes de nuestro tiempo: los Estados Unidos y Europa. Ambos son los padres de la "occidentalidad”, pero ningún progenitor podrá por sí sólo mantener con vida al niño. Los EEUU están aquí frente a grandes desafíos.

En un mundo de transformaciones y reagrupaciones, el excepcionalismo estadounidense ${ }^{70}$ cada vez tiene menos sentido. La desilusión mundial ante los Estados Unidos ha alcanzado también a aquellas elites que creían firmemente en el modelo norteamericano. El desencanto ante las formas de acción de los norteamericanos se ha convertido en un legado negativo difícil de desmontar. Es de llamar la atención su falta de capacidad para integrarse de una manera inteligente y más o menos justa en la multiplicidad del mundo global. ${ }^{71} \mathrm{Si}$ el país logra replegarse, incluso en la esfera política, de modo que actúe confor-

67. Polymeropoulos, Elli y Markus Tidten, "Japan - marginalisiert und unnötig? Ein politisches System zerfällt", SWP-Aktuell, núm. 84, diciembre, 2008.

68. Ministerio de Relaciones Exteriores, "Japón: Wirtschaft". En Internet. Fecha de consulta: 7.2.2009.

69. Véase Nabers, Dirk, "Neorealistische Missverständnisse: Japan, China und die Region Südostasien", Japan Aktuell, núm.1, 2008, pp. 56-72; Julie Wilson, "Complex regional multilateralism: "strategising" Japan's response to Southeast Asia", The Pacific Revies, 17/1, marzo, 2004, pp. 71-94.

70. Véase Hodgson, Godfrey, The Myth of American Exceptionalism, New Haven y Londres, 2009.

71. Véase Mahbubani, Rehabilitating America, op. cit., pp. 20-21. 
me a la lógica de un primus inter pares y comprenda el concepto de "pares" , y por tanto acepte tanto a los europeos como a los países asiáticos con mayor liderazgo, entonces se conservará mucho de la esencia de la occidentalidad. El nuevo presidente norteamericano puede intentar de manera realista un cambio en las formas de pensamiento. ${ }^{72}$ Hace años, Samuel Huntington describió a los Estados Unidos como una "lonely superpower". ${ }^{73} \mathrm{Si}$ los Estados Unidos desean permanecer en el siglo XXI como una potencia en la política mundial tomada en serio, debe conducirse como una potencia conciliatoria y no como un poder que busca fundamentalmente imponer sus propios intereses nacionales. Pues el control del mundo — según la advertencia del politólogo de Harvard recientemente fallecido- ya no será posible a partir de un solo lado.

El siguiente desarrollo del mundo Asia-Pacífico y sus pretensiones globales depende, por una parte, no sólo de un retroceso parcial de los Estados Unidos, sino también de la propia capacidad de las fuerzas orientales del Pacífico de crecer de manera conjunta e influir de manera convincente en el mundo. Si esto es posible ante las diferencias culturales internas con sus fracturas ideológicas y religiosas, es una cuestión que aquí dejamos abierta. El Occidente, sobre todo los EEUU, no debe caer en la tentación de entrar a un "clash of civilizations", que quizás no perdería, pero del que seguramente tampoco saldría ganador. "La moneda basal del mundo actual —escribe el editor de la revista Current History, Alan Sorensen $-{ }^{74}$ es el poder blando, la capacidad de convencer a los demás de las propias formas de pensamiento". Norteamérica ya no puede recibir este crédito. Pero, si en este sentido ha perdido parte considerable de su poder hegemónico, ¿puede conservar al menos su papel dirigente? La respuesta sólo puede ser: sí, pero no solos.

Europa podría convertirse en un desafío todavía mayor para Estados Unidos que China o Asia. ${ }^{75}$ Pues la oportunidad de mantener partes esenciales de la occidentalidad depende de un estrecho compromiso recíproco entre Europa y los EEUU. Ya con bastante anterioridad al gobierno de George W. Bush,

72. Véase Khanna, Parag, "Waving Goodbye to Hegemony", The New York Times Magazine, enero 27, 2008, pp. 34-66.

73. Huntington, Samuel, "The Lonely Superpower", Foreign Affairs, 78/2, marzo-abril, 1999, pp. 35-49.

74. Sorensen, "A Panic Made in America", Current History, enero, 2009, pp. 3-9, aquí p. 9.

75. Sobre las dificultades en las relaciones EeuU-Europa véase Kupchan, Charles A., "The rise of Europe, America's Changing Internationalism ant the end of us Primacy", Political Science Quarterly, 118/2, 2003, pp. 205-231. 
los EEUU habían aprendido a mirar hacia abajo a Europa. Fuera de algunos periodos excepcionales - como por ejemplo Francia o Alemania occidental bajo Helmut Schmidt o Gerhard Schröder-, la Europa continental occidental era considerada dócil, dispuesta a hacer lo que se le pidiera. Sin menoscabo de un colorido local de diferente tono, en Europa se asimiló el estilo de vida y de entretenimiento norteamericano, lo que se manifiesta diariamente, entre otras cosas, en los programas de televisión alemanes. La división social y de estatus de las sociedades fue vista como un atributo prefabricado en los Estados Unidos, inevitable en una sociedad capitalista en crecimiento. En el Tratado de Boloña se invirtió la polaridad de un sistema educativo tan exitoso y ejemplar como el de Alemania ${ }^{76}$ y los estándares anglosajones. El error fue entendido más rápido por los intelectuales europeos que por los políticos. Un artículo de la revista Der Spiegel del año de 2003 con el título "La potencia presuntuosa", ${ }^{77}$ puede ser considerado como pars pro toto de las diversas críticas que en el presente van en aumento.

La pregunta aquí es, ¿cuál es el potencial de conformación en este mundo de cambios que puede ofrecer Europa? Antes de buscar una respuesta, hay que aclarar que este artículo no intenta presentar a Europa como modelo para un futuro orden mundial. El potencial de conformación de Europa dependerá de su disposición a rechazar claramente situaciones globales cuestionables, pues sólo entonces existe la posibilidad de asumir con éxito los desafíos políticos provenientes de Estados Unidos y Asia. Aquí menciono algunos puntos de orientación para un orden mundial futuro desde el punto de vista europeo.

1. Ya desde el siglo XIX en Europa — primero en Alemania y luego en Escandinavia y los Países Bajos, Bélgica y Luxemburgo - se ha conceptualizado al Estado como un Estado social, esto es quizás el mayor logro civilizatorio de Europa desde hace siglo y medio.

2. Después de largos conflictos sangrientos y vergonzosos de diversa naturaleza, Europa ha aprendido a convivir sin violencia ante la complicada pluralidad europea con sus diferencias étnicas, distintas visiones del mundo y religiones y con sus desigualdades en el poder político.

3. Paso a paso, Europa ha sacado las consecuencias de las caras enseñanzas del pasado. La renuncia parcial a la soberanía del Estado nacional a favor

76. Lo mismo se puede decir del de Francia o los países escandinavos.

77. Edición número12 del 17.3. 2003. 
de la Unión Europea, el club del euro y la libre circulación de personas y capitales son dignos de atención en muchos países y se discute su viabilidad como modelos a seguir.

4. Los gobiernos europeos no son los ideales, pero por lo general son capaces de actuar y se puede confiar en ellos.

5. En Europa se ha desarrollado lo que en las ciencias políticas llamamos "política de varios niveles".

6. De ahí que se piense en Europa cada vez más en categorías y compromisos trasnacionales, es decir, Europa está bien preparada para participar en redes estructurales de la política internacional, la economía y la cultura, a lo que han contribuido las fundaciones políticas alemanas.

7. Debido a que detrás de todo esto se encuentra la idea de que Europa tiene una reducida disposición a la violencia, Europa ha logrado disipar casi completamente la desconfianza internacional de décadas y generaciones pasadas.

8. No existen muchas naciones en el mundo donde la "sociedad" se pueda desarrollar de forma tan libre como en Europa y esto también en relación al "Estado". El Estado europeo, con todas las diferencias entre países, actúa de forma democrática y constitucional. Para garantizarlo ha desarrollado un aparato de administración de justicia que atiende las relaciones entre "Estado" "sociedad" e "individuos".

9. Finalmente, Europa puede ofrecer nuevas ideas, para lo que está bien preparada gracias a su pluralidad interna.

Seguramente éstas no son las únicas características de la occidentalidad en Europa, pero sí las esenciales, y que, con todo respeto a la cultura asiática, irradian una mayor fuerza de convencimiento a nivel mundial que lo que pueden ofrecer en el presente China, India e Indonesia. También los EEUU sólo pueden prescindir de ellas abandonando a los contenidos de la occidentalidad a favor de una política hegemónica cruda. Esto significa, por un lado, que se ha llegado al fin del siglo norteamericano en su forma dominante y que, por otro lado, no se puede renunciar a una occidentalidad integral si se tiene en mente un futuro deseable para la humanidad. Europa no puede dejarse empujar a un rincón como si fuera una entidad envejecida, como lo insinuó Rumsfeld, y en ocasiones lo evoca también Mahbubani.

Europa tiene que conducirse ante Estados Unidos más segura de sí misma y de manera más exigente. En los marcos de la categoría de occidentalidad 
debe reflexionar sobre sus fortalezas y articularlas claramente, sin que por ello parezca aleccionadora. Por el momento, Europa es la única fuerza donde se mueven elementos para un reinicio socioeconómico y político, por ejemplo, en las doctrinas sociales de las dos grandes iglesias, en la reafirmación alemana de la economía social de mercado, en los círculos académicos que no están paralizados por patrones de pensamiento, etc. Esta dinámica se puede expresar todavía de una forma más plástica y comparativa: por el momento ninguna otra región del mundo, incluyendo Asia, podría formular un documento tan amplio sobre los derechos humanos y de los ciudadanos, como el que se presentó hace 20 años en la Conferencia sobre la Seguridad y la Cooperación en Europa.$^{78} \mathrm{Su}$ calidad apenas se puede comparar con el programa de reformas propuesto en la "Carta 08", firmada por cientos de personalidades en China que busca poner fin a la dictadura del partido. Esta Carta nunca encontró aplicación, pues esto significaría un cambio radical y absoluto del sistema político autoritario. Además, existe una amplia defensa política y cultural ante la modernidad, ${ }^{79}$ reconocida en numerosos documentos internacionales, que no arriesga canje alguno.

Seguramente no hay que rebasar el catálogo de virtudes y ventajas de Europa, como se lee en las obras de Mark Leonard ${ }^{80}$ o Manuel Todd.$^{81}$ El mundo del futuro no será uniformemente democrático, liberal y orientado a la libertad, sino diverso, contradictorio y conflictivo. Y por un largo tiempo - quizás para siempre- comprenderá diversos sistemas de valores y modelos de desarrollo. ${ }^{82}$ Sin embargo, en sus rasgos fundamentales permanecerá estrechamente unido a las características occidentales. Europa está mucho mejor equipada que los Estados Unidos para equilibrar fuerzas y experiencias, encontrar compromisos, desarrollar formas de convivencia no discriminadoras, incluso descubrir impulsos esenciales para la convivencia en este planeta. Los Estados Unidos han considerado a la occidentalidad más bien como el fin de la historia en el sentido

78. Impreso bajo el título "1. Dokument des Treffens der Konferenz über die menschliche Dimension der KSZE in Kopenhagen vom 29.61992", en Dieter Senghaas, Friedensprojekt Europa, Francfort, 1992, pp. 191-222: véase también ahí el capítulo introductorio "Europa, quo vadis?", pp. 15-82.

79. Véase Senghass, Dieter, "Die Wirklichkeit der Kulturkämpfe”, en Joas, Hans y Klaus Wiegandt (editores), Die Kulturellen Werte Europas, Francfort del Meno, $2^{\mathrm{a}}$ edición 2005, pp. 444-468.

80. Véase del mismo autor "Why Europe will run the 21st century, Londres, 2005.

81. Véase del mismo autor Weltmacht USA. Ein Nachruf, Munich y Zürich, $2^{\mathrm{a}}$ edición 2003.

82. Véase Cagan, Robert, "History Back. Ambitious autocracias hesitant democracies", The Weekly Standard, agosto, núm. 25, 2008, pp. 18-23. 
de Fukuyama que una oferta de modernización. Hasta ahora no han surgido modelos de civilización alternativos con un soft power que desde Asia ejerza su influencia en el mundo. Y una última frase sobre nuestro tema: como sea que se entienda y se conforme el mundo futuro, la fuerza analítica y la practicabilidad siguen siendo virtudes indispensables cuando se requiere un alto grado de precaución cultural y hermenéutica. En este punto Europa está más dispuesta y es más capaz de aprender que muchas otras regiones. ${ }^{83}$ m

83. Véase Dosch, Jörn, Manfred Mols, Rainer Öhlschläger (editores), Staat und Demokratie in Asien. Zur politischen Transformation einer Weltregion, Berlín y Münster, 2007. 